\title{
Mesenchymal stromal cells ameliorate acute lung injury induced by LPS mainly through stanniocalcin-2 mediating macrophage polarization
}

\author{
Haijin Lv ${ }^{1,2 \#}$, Qiuli Liu ${ }^{2,3 \#}$, Yao Sun ${ }^{1 \#}$, Xiaomeng Yi ${ }^{1}$, Xuxia Wei ${ }^{1}$, Wei Liu $^{2,4}$, Qi Zhang ${ }^{2,3}$, Huimin Yi $^{1}$, \\ Guihua Chen ${ }^{4,5}$
}

${ }^{1}$ Surgical and Transplant Intensive Care Unit, The Third Affiliated Hospital of Sun Yat-sen University, Guangzhou 510630, China; ${ }^{2}$ Key Laboratory of Liver Disease Biotherapy and Translational Medicine of Guangdong Higher Education Institutes, Sun Yat-sen University, Guangzhou 510630, China; ${ }^{3}$ The Biotherapy Center, ${ }^{4}$ Guangdong Provincial Key Laboratory of Liver Disease Research, The Third Affiliated Hospital of Sun Yat-sen University, Guangzhou 510630, China; ${ }^{5}$ Department of Hepatic Surgery and Liver Transplantation Center, The Third Affiliated Hospital, Organ Transplantation Institute, Sun Yat-sen University, Guangzhou 510630, China

Contributions: (I) Conception and design: Q Zhang, H Yi, G Chen, X Yi, X Wei, W Liu; (II) Administrative support: G Chen; (III) Provision of study materials or patients: H Lv, Q Liu, Q Zhang; (IV) Collection and assembly of data: H Lv, Q Liu, Y Sun; (V) Data analysis and interpretation: H Lv, Q Liu, Y Sun; (VI) Manuscript writing: All authors; (VII) Final approval of manuscript: All authors.

\#These authors contributed equally to this work.

Correspondence to: Qi Zhang. The Biotherapy Center, The Third Affiliated Hospital of Sun Yat-sen University, Guangzhou 510630, China. Email: kee_kee@126.com; Huimin Yi. Surgical and Transplant Intensive Care Unit, The Third Affiliated Hospital of Sun Yat-sen University, Guangzhou 510630, China. Email: yhmsysu@163.com; Guihua Chen. Guangdong Provincial Key Laboratory of Liver Disease Research, The Third Affiliated Hospital of Sun Yat-sen University, Guangzhou 510630, China. Email: chgh1955@263.net.

Background: Acute lung injury (ALI) is a devastating syndrome with no effective pharmacological therapies in the clinic. Mesenchymal stromal cells (MSCs) have been demonstrated to promote inflammation resolution and tissue repair in ALI. However, the specific mechanisms of this have not been clearly elucidated. Stanniocalcin-2 (STC2) is a stress-responsive protein that has anti-oxidative properties. Our previous study found that STC2 is a highly expressed stanniocalcin in MSCs, which may be involved in immunomodulatory activities. However, the role of STC2 in MSCs to resolve ALI has never been elucidated.

Methods: Specific shRNA was used to downregulate STC2 in MSCs. We detected ROS, cell apoptosis, and paracrine factors changes in MSCs. STC2-associated antioxidant genes were also investigated by Coimmunoprecipitation (Co-IP) and immunofluorescence. Macrophage (THP1 cells) phenotype transitions were measured by flow cytometry after coculturing with MSCs in vitro. Then, we used MSCs to treat LPSinduced ALI in mice, and assessed injury scores inflammation, and antioxidant activities in the lungs of the mice. Alveolar macrophage (AM) phenotypes and CFSE-labeled MSC apoptosis in collected bronchoalveolar fluids (BALF) were also analyzed by flow cytometry.

Results: After the STC2 knockdown, MSCs increased ROS generation and cell apoptosis after PX12 pretreatment. The antioxidant protein Nrf2 was colocalized with STC2 in the nucleus. A lack of STC2 expression in MSCs produced less interleukin 10 (IL10) and blunted macrophage polarization in THP1 cells. Furthermore, in the murine LPS-induced ALI model, the STC2 knockdown counteracted the inflammatory resolution and antioxidative effect of MSCs in the lungs. MSC ${ }^{\text {shSTC2 }}$-treated mice had a higher lung injury score than the controls, which may be attributed to diminished AM polarization and increased apoptosis of MSCs in vivo.

Conclusions: Collectively, these results suggested that STC2 is essential to the anti-oxidative and antiinflammation properties of MSCs and could prove to be crucial for stem cell therapies for ALI.

Keywords: Stanniocalcins-2 (STC2); mesenchymal stromal cells (MSCs); macrophage; apoptosis; acute lung injury (ALI) 
Submitted Nov 29, 2019. Accepted for publication Feb 05, 2020.

doi: 10.21037/atm.2020.02.105

View this article at: http://dx.doi.org/10.21037/atm.2020.02.105

\section{Introduction}

Acute lung injury (ALI)/acute respiratory distress syndrome (ARDS) is a devastating clinical syndrome, which among critically ill patients has high morbidity (1-3). Bacterial endotoxin, virus-induced sepsis, pneumonia, aspiration, and trauma are common causes of ALI (1). Pathophysiologically, ALI is characterized by diffuse epithelial and endothelial damage and subsequent inflammatory cellular and proteinrich effluxes in the airspace $(1,4)$. Until recently, limited supportive interventions were the only effective drug treatment for $\operatorname{ALI}(5,6)$.

Many studies have shown that alveolar macrophages (AMs), either tissue-resident or recruited, are crucial in orchestrating the initiation and resolution of lung inflammation $(7,8)$. AMs recognize pathogen-associated stimulus (e.g., LPS) via toll-like receptors (TLRs)/the NF$\kappa \mathrm{B}$ pathway and can be classified as M1 phenotype which releases proinflammatory cytokines. These cytokines further recruit neutrophils and monocytes and are essential in clearing pathogens from the airways. However, in ALI, the inflammation is not merely terminated when the pathogens are cleared or declined $(7,9)$. Switching to an alternative phenotype (M2) could promote the resolution of lung inflammation and tissue repair (10), which could be a potential strategy in treating ALI.

Mesenchymal stem cells (MSCs) are a class of adult stem cells with low immunogenicity and multipotential differentiation potentials. MSCs are widely used in immune disorders and tissue injuries, typically in acute lung injuries $(11,12)$. Cumulative evidence has revealed that MSCs repair injured lungs via paracrine or direct contact with target cells rather than through direct differentiation (12). MSCs restore the alveolar barrier function by reducing epithelial and endothelial apoptosis by secreting KGF, Ang1, and HGF $(13,14)$. MSCs can also modulate lung inflammation by releasing soluble paracrine factors. Macrophages are crucial for the initiation and development of ALI. MSCseducated macrophages reduce alveolar inflammation by promoting macrophage polarization (15). However, the details of the mechanisms underpinning this are yet to be fully interpreted.

Intravenous or intrapulmonary administration of MSCs presents a "hit and run" phenomenon in the lung and survives for only a short time in vivo $(16,17)$, dampening its persistent efficacy. Apoptotic or inviable MSCs diminishes animal lung injury repair and clinical efficacy via reduced immunomodulatory and pro-survival properties (18-20). In recent years, oxidative stress components in MSCs were found to be involved with both anti-apoptotic and anti-inflammatory effects. Several antioxidative genes like SOD, CAT, STC1, HO-1, and Nrf2, which are expressed in MSCs, have been reported to promote the resolution of inflammation and maintain MSCs survival in vivo. Strategies for enhancing the in vivo activity of MSCs have been proposed (21-23), but the key elements should be expounded first.

STC1 and STC2, the members of the stanniocalcin (STC) family, first reported as systemic regulators in calcium metabolism, are widely expressed in vertebrate tissues (24). STCs, also known as stress-responsive proteins, play an important role in oxidative stress, angiogenesis, anti-inflammation, and anti-apoptosis (25-31). Previous non-tumor-related investigations were mostly focused on STC1. More recently, however, STC2, a 56 KD homolog glycoprotein hormone of STC1, has also been shown to have both pro-survival and anti-inflammatory qualities $(25,29,30,32-34)$. STC2 enhances mesenchymal stem cell survival by suppressing oxidative stress (33) and has been shown to reduce the levels of tumor necrosis factor- $\alpha$ (TNF- $\alpha$ ) and IL-1 $\beta$ in LPS-treated BV2 cells (34). Our previous study also revealed that STC2 contributes to MSCs attenuating murine contact hypersensitivity mainly by reducing CD8+ Tc1 cells (30). However, whether STC2 is involved in the survival and macrophage polarization of MSCs in ALI has not yet been clarified.

In this study, we investigated the relationship between STC2 expression in MSCs and its anti-apoptotic and antiinflammatory properties, exploring its potential role in MSC-based treatment for ALI.

\section{Methods}

\section{MSCs isolation}

MSCs were isolated from bone marrow samples of healthy 
volunteers following a previous established method (30). The samples were obtained in adherence to the Declaration of Helsinki protocols and with informed consent, and the study received approval from the Ethics Committee of the Third Affiliated Hospital of Sun Yat-sen University. Mononuclear cells were firstly acquired using FicollHypaque (GE, http://www3.gehealthcare.com) density gradient centrifugation. The cells were then seeded in $75-\mathrm{cm}^{2}$ flasks (CellBIND, Corning) and cultured for 72 hours. When the MSCs reached $70-80 \%$ confluence, they were obtained using $0.125 \%$ trypsin and then seeded in a $75-\mathrm{cm}^{2}$ dish at a density of $1 \times 10^{4}$ cells $/ \mathrm{cm}^{2}$. The cells were identified in our previous report (30).

\section{The collection of LPS-induced ALI mouse model and bronchoalveolar lavage fluid (BALF)}

Eight-to-ten-week-old male BALB/c mice were obtained from the Biomedical Research Institute of Nanjing University. The study and all procedures were approved by the Animal Care and Use Committee of the Animal Welfare Ethics Committee of Sun Yat-sen University Vaccine Research Institute (approval number IACUC-F3-16-0401). All the mice were kept in a temperature-regulated (22$25^{\circ} \mathrm{C}$ ) room on a 12 -h light/dark cycle. The mice were divided at random into four different groups $(\mathrm{n}=10$ each group): the PBS + PBS, LPS + PBS, LPS + MSC ${ }^{\text {shNTC }}$, and LPS + MSC ${ }^{\text {shSTC2 }}$ groups. The control group (only PBS) was not shown in results due to the similar injury level with PBS + PBS group (Figure S1). The ALI model was established by intranasal instillation of $30 \mu \mathrm{L}$ LPS $(5 \mathrm{mg} / \mathrm{kg}$ ) (Sigma, L4524). $10^{7}$ cells/mL MSC MSNTC $^{\text {shN }}$ MSC $^{\text {shSTC2 }}$ suspended in 30pl PBS were instilled 4 hour later. The corresponding control groups received the same volume of $30 \mu \mathrm{L}$ PBS. The mice were sacrificed to obtain lung tissues or collect BALF $24 \mathrm{~h}$ after LPS or PBS treatment. For apoptosis analysis in vitro, BALF were collected 24 or $48 \mathrm{~h}$ after LPS or PBS administration.

BALF was collected through cannulation of the trachea using a 30-gauge infusion needle and flushing the lung 3 times with $0.5 \mathrm{~mL}$ ice-cold PBS. The BALF was centrifuged $500 \mathrm{~g}$ for $10 \mathrm{~min}$ at $4{ }^{\circ} \mathrm{C}$. The pellets were resuspended in cold PBS and the total cell number was counted was with a hemocytometer or analyzed by flow cytometry. The neutrophil count was calculated out using Wright-Giemsastained smears. Protein levels of interleukin-17A and TNF- $\alpha$ in the BALF were quantified by specific enzymelinked immunosorbent assay (ELISA) kits (Boster Biological
Technology Co., Ltd., China) according to standard protocols.

\section{Co-culture experiments}

MSCs were seeded on a $0.4 \mu \mathrm{m}$ Transwell inserts (Millipore) at a concentration of $4 \times 10^{5} / \mathrm{mL}$. THP 1 cells (ATCC) $\left(2 \times 10^{5} / \mathrm{mL}\right)$ were cultured in the lower compartment of a 6-well flat-bottom plate, with $50 \mathrm{ng} / \mathrm{mL}$ PMA added to the culture medium. After $24 \mathrm{~h}$, the Transwell-cultured MSCs were transferred to the 6-well flat plate containing the THP1 (ATCC) cells. Then, $1 \mu \mathrm{g} / \mathrm{mL}$ LPS and $50 \mathrm{ng} / \mathrm{ml}$ IFN- $\gamma$ were added to the co-culture system for a period of $24 \mathrm{~h}$, before the THP1 cells were collected using $0.5 \mathrm{mM}$ EDTA for subsequent analysis.

\section{ROS assessment and immunofluorescence}

The MSCs were harvested using $0.125 \%$ trypsin, and total intracellular ROS were detected using CellROX Deep Red Reagent (Molecular Probes, Life Technologies, Carlsbad, CA, USA), according to the manufacturer's protocol, and analyzed by flow cytometry.

The MSCs were fixed in 3.7\% formaldehyde for $20 \mathrm{~min}$, permeabilized in $0.1 \%$ Triton $\mathrm{X}-100$ for $10 \mathrm{~min}$, and incubated with primary antibody overnight at $4{ }^{\circ} \mathrm{C}$. Then, the cells were treated with secondary antibodies for $1 \mathrm{~h}$ at room temperature. DAPI (Invitrogen) was used to stain nuclear DNA. The antibodies used in the immunofluorescence assay were as follows antiSTC2 (Abcam, UK, 1:100) and anti-Nrf2 (Abcam, UK, 1:200). Images were acquired using an LSM700 confocal microscope (Zeiss).

\section{Flow cytometry analysis}

The percentage of apoptotic MSCs were evaluated using a fluorescein isothiocyanate (FITC) Annexin V Apoptosis Detection Kit I (BD Pharmingen) according to the manufacturer's instructions. MSCs were collected and underwent incubation with PI and annexin V-FITC at $37{ }^{\circ} \mathrm{C}$ for $15 \mathrm{~min}$ away from the light.

THP1 cells were acquired to incubate with primary antibody against anti-human CD14-FITC (BD bioscience, USA), CD206-APC (BD bioscience, USA), IL-10-efluor 660 (eBioscience, USA), and TNF- $\alpha-\mathrm{PE}$ (Biolegend, USA) at $4{ }^{\circ} \mathrm{C}$ for $30 \mathrm{~min}$, protected from the light. TNF- $\alpha$ and IL10 cytokine staining were conducted according to the 
intracellular cytokine staining protocol. Murine BALF cells were cultured for an additional 24 hours after collection and stained with anti-mouse F4/80-BV421, TNF- $\alpha-\mathrm{PE}$, CD206-FITC antibodies (BD bioscience, USA). Flow cytometry assay was conducted with a BD LSR II flow cytometer. Data were analyzed by the Flowjo7.6 software (Becton Dickinson).

\section{Co-IP assay}

MSCs were lysed using NE-PER ${ }^{\mathrm{TM}}$ Nuclear and Cytoplasmic Extraction Reagents (Thermo Scientific, $78833)$, lysates (1 $\mathrm{mg}$ protein) were pre-cleared with $20 \mu \mathrm{L}$ of Protein G Agarose beads (Santa Cruz) for 2-4 h, and then the supernatants were collected by centrifugation at 3,000 rpm at $4{ }^{\circ} \mathrm{C}$ for $3 \mathrm{~min}$. The supernatants mixed with the Nrf2 antibody and beads were rotated overnight at $4{ }^{\circ} \mathrm{C}$. After being washed with NP-40 buffer for three times, the immunocomplexes were eluted by boiling in $1 \times$ SDS-loading buffer for $10 \mathrm{~min}$. Then, the buffer was separated using sodium dodecyl sulfate-polyacrylamide gel electrophoresis (SDS-PAGE) and electroblotted onto a polyvinylidene fluoride (PVDF) membrane (Roche, Basel, Switzerland) in line with standard procedures. Transferred blots were incubated sequentially with the STC2 antibody (Aabcam, UK) and Nrf2 antibody (Proteintech, USA) at $4{ }^{\circ} \mathrm{C}$ for 12 hours, and HRP-conjugated secondary antibodies. Protein bands were visualized with an enhanced chemiluminescence detection kit and recorded on a radiographic film (Alpha Innotech, San Jose, CA, USA).

\section{RNA isolation and $q R T-P C R$ assays}

MSCs were transfected with shSTC2 synthesized in our previous studies (30). Total RNA was extracted using Trizol reagent (Invitrogen, Shanghai, China). Then, $1 \mu \mathrm{g}$ of total RNA was reverse-transcribed to cDNA using HiScript Q RT Supermix (Vazyme, Jiangsu, China). Finally, $1 \mu \mathrm{L}$ of cDNA was used for qRTPCR analysis using ChamQ SYBR qPCR Master Mix (Vazyme, Jiangsu, China). The primer sequences were as follows: STC2, 5'-CTGTCCCTGCAGAATACAGC-3' and 5'-AGTGACTGAAACGTAGCCGA-3 '; Nrf2, 5'-AGGTTGCCCACATTCCCAAA-3' and 5' -AGTGACTGAAACGTAGCCGA-3'; HO-1, 5 ' - GAAGAGCACTGATCGTACTGGC-3' and 5'-GGATACTGAAAGTTCGCAGGG-3'. All reactions were run in triplicate. The $\Delta \Delta \mathrm{Ct}$ method and relative changes of mRNA levels were obtained by normalization GAPDH relative to the control.

\section{Histological examination}

The mouse lungs were fixed by neutral buffered formalin solution for at least 24 hours and subsequently transferred to $70 \%$ ethanol until processing. Fixed tissues were then dehydrated in graded ethanol, cleared in xylene, and mounted in paraffin, followed by sectioning at $5 \mu \mathrm{m}$ and staining with hematoxylin and eosin ( $\mathrm{H} \& \mathrm{E})$. The lung tissue pathology was observed by light microscopy. The severity of lung injury was assessed mainly by the methods reported in the literature (4). Briefly, each section was scored according to the following five items: (I) Neutrophils in the alveolar space; (II) Neutrophils in the interstitial space; (III) Hyaline membranes; (IV) Proteinaceous debris is filling the airspaces; and (V) Alveolar septal congestion. Each section was scored from the sum of the five items according to the injury field. The resulting injury score was between zero and one.

\section{Lung microvascular permeability}

Lung microvascular permeability was determined by the Evans Blue dye method (4). $20 \mathrm{mg} / \mathrm{kg}$ of Evans blue dye (Sigma-Aldrich, USA) was dissolved in $250 \mu \mathrm{L}$ PBS and injected into the tail vein of the mice $24 \mathrm{~h}$ after ALI model preparation. Thirty minutes later, the mice were anesthetized with pentobarbital sodium and then perfused with $10 \mathrm{~mL}$ PBS to remove the blood. The right lung lobe was weighted, incubated, and homogenized with formamide (Sigma-Aldrich, USA) for $24 \mathrm{~h}$ at $60^{\circ} \mathrm{C}$. EB concentration ( $\mu \mathrm{g} / \mathrm{mg}$ tissue) was determined in the supernatant with a spectrophotometer at $620 \mathrm{~nm}$ for absorbance against a standard curve.

\section{Superoxide dismutase activity assay and biochemical assay}

Lung tissues and MSCs were homogenized in tissue lysis buffer $(0.01 \mathrm{mmol} / \mathrm{L}$ Tris-HCl, Ph7.4, $0.1 \mathrm{mmol} / \mathrm{L}$ EDTA$2 \mathrm{Na}, 0.01 \mathrm{~mol} / \mathrm{L}$ sucrose, $0.8 \% \mathrm{NaCl})(35)$ at $4{ }^{\circ} \mathrm{C}$. The homogenate was centrifuged at $10,000 \times \mathrm{g}$ for $10 \mathrm{~min}$ at $4{ }^{\circ} \mathrm{C}$, and the supernatant was collected for the following experiment. Total super oxidative dismutase (SOD) activity (U/g tissue) was then detected using the total superoxide dismutase assay kit with NBT (S0109, Beyotime Institute of Biotechnology, Jiangsu, China) following the manufacturer's instructions. The concentrations of reduced glutathione (GSH) 
and oxidized glutathione disulfide (GSSG) were measured and GSH/GSSG ratio was calculated by an enzymatic method according to the commercial assay kit procedure (Beyotime Institute of Biotechnology, Jiangsu, China).

\section{Statistical analysis}

Unless otherwise stated, results are shown as mean \pm standard deviation (SD) based on at least three independent experiments. Statistical significance $(\mathrm{P}<0.05)$ was considered by one-way analysis of variance (ANOVA) with an appropriate correction or Student's $t$-test using SPSS 19.0 statistical and Prism 7.0 Graphpad software.

\section{Results}

STC2 knockdown attenuated the antioxidant and antiapoptosis of MSCs

To explore the role of STC2 in MSC-mediated antioxidation, we depleted STC2 expression in MSCs using a lentiviral packaging system containing STC2-specific shRNA based on our previous report (30). RT-PCR and Western blotting revealed that STC2 mRNA and protein expression were lower in knockdown cells (MSC ${ }^{\text {shSTC2}}$ ) compared with control-transfected MSCs (MSC ${ }^{\text {shNTC }}$ ) (Figure S2). Then, we analyzed the possible role of STC2 in MSC suppression of reactive oxygen species (ROS). As was expected, MSC $\mathrm{ChSTC2}^{\mathrm{sh}}$ significantly increased the expression of ROS compared with MSC ${ }^{\text {shNTC }}$ (Figure 1A). The results indicated that STC2 might be involved in MSC-mediated antioxidative function. Meanwhile, we observed that MSC $^{\text {shSTC2 }}$ had higher levels of apoptosis after the oxidative insult of PX12, relative to MSC $^{\text {shNTC }}$ (Figure 1B). These results revealed that STC2 is essential for MSCs-related antioxidative activity and anti-apoptosis under stress.

\section{The STC2/Nrf2 patbway was involved in MSCs-mediated antioxidative processes}

Our previous study found the colocalization of STC2 with antioxidant enzymes heme oxygenase-1 (HO-1) in the nucleus, influencing its activity (30). Here, we found that the expressions of nuclear factor erythroid 2 -related factor $2(\mathrm{Nrf} 2)$ and HO-1 were reduced when the STC2 level downregulated (Figure 2A). Next, we use immunofluorescence staining technology to explore the distribution of STC2 and Nrf2. Our results showed that Nrf2 was localized in the cell nucleus, while STC2 was expressed in both the nucleus and cytoplasm, as observed by confocal fluorescence microscopy (Figure 2B). To further analyze the interaction between STC2 and Nrf2, as well as their role in MSCsmediated antioxidative activity, we designed several overexpression constructs of STC2 compared with MSCs-Control (MSCs mock vector) (Figure S3), including FL (full-length), STC2 1-300 fragment (overexpression bases 1-300, same as below), STC2 1-540 fragment, STC2 1-600 fragment, STC2 540-600 fragment, and STC2 600-900 fragment. Then we transfected $\mathrm{MSC}^{\text {shSTC2 }}$ with these constructs and investigated their expression level in the nucleus and cytoplasm. We found that STC2 600-900 fragment was mostly located in the nucleus (Figure S4). Therefore, we speculated that the binding site for Nrf2 was mainly located in the amino acids 200-300 of STC2. A similar result was obtained by CoIP analysis (Figure 2C). As far as we are aware, this is the first time the interaction between STC2 and Nrf2 has been revealed. These results demonstrated that STC2 might be involved in the antioxidative processes in MSCs.

\section{MSCs-derived STC2 attenuated the proinflammatory cytokine production of macrophages}

AMs play an essential role in recognizing and clearing pathogens from the airways to suppress the inflammatory reaction and oxidative stress in lung injury (10). AMs have considerable diversity and plasticity and can be classified as M1 phenotype, which is induced by LPS or IFN- $\gamma$ and secretes proinflammatory cytokine TNF- $\alpha$, or as M2 subtypes, expressing anti-inflammatory M2 markers (e.g., CD206 and IL-10) stimulated by IL-4/IL-13 (7). MSCs have been reported to alleviate lung injury by regulating AMs (19). We used ELISA to detect paracrine factors in cultured cell supernatant and the results showed that STC2deficient MSCs had reduced IL-10 but not TSG6 (Figure S5). Furthermore, to investigate whether STC2 regulated MSCs apoptosis could affect the AM, firstly, we cocultured apoptotic MSCs (apo-MSCs) or normal MSCs with THP1 and found that apo-MSCs diminished macrophage polarization by inducing lower CD206 and higher TNF- $\alpha$ levels (Figure S6). Then MSC ${ }^{\text {shNTC }}$ or MSC ShSTC2 $^{\text {shere }}$ cocultured with THP1 to explore the role of STC2 in AM polarization. As expected, MSC $^{\text {shNTC }}$ significantly inhibited TNF- $\alpha$ and increased IL-10 or CD206 expression in THP1 cells. Remarkably, the STC2 knockdown in MSCs restored 
A

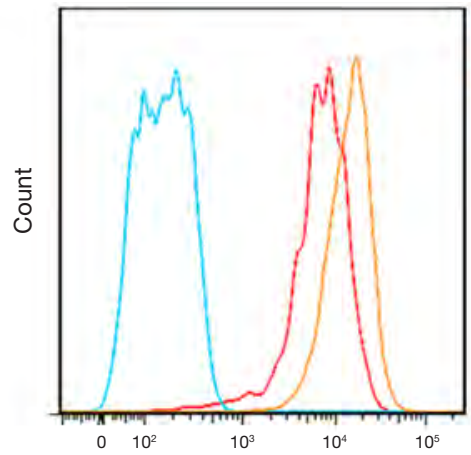

CellROX'M Deep Red Reagent Fluoresence

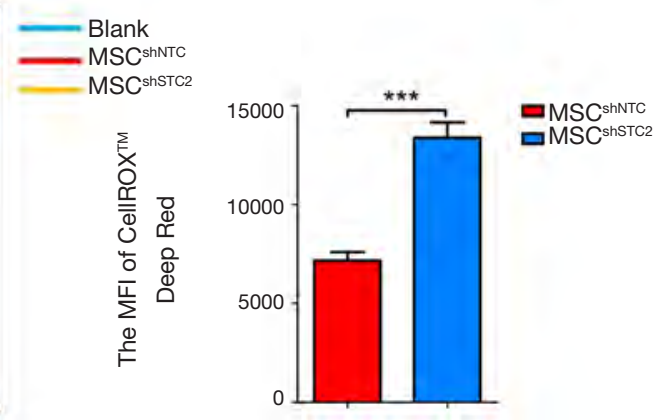

B
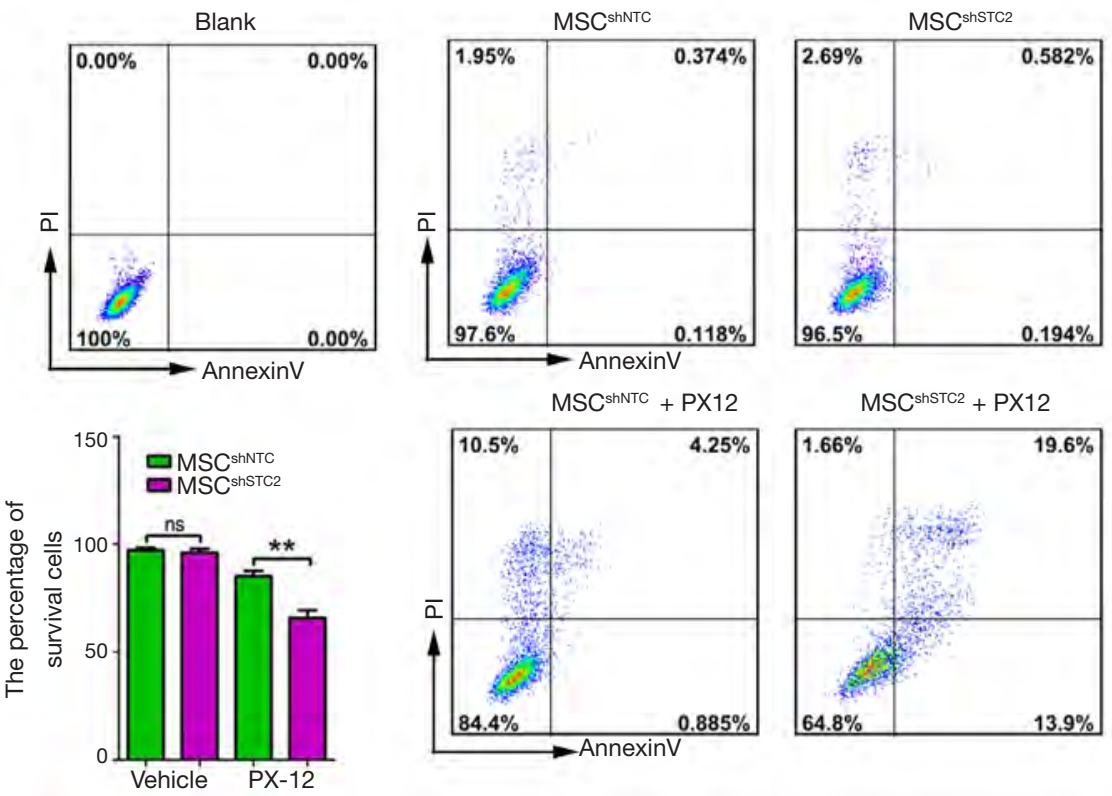

Figure 1 MSC-derived STC2 reduced the generation of ROS and apoptosis rate. STC2-specific shRNA lentivirus packaged stable cell was constructed. (A) The ROS levels in MSC ${ }^{\text {shNTC }}$ and MSC $^{\text {shSTC2 }}$ were measured using kits and analyzed by flow cytometry; (B) MSC ${ }^{\text {shNTC }}$ and MSC $^{\text {shSTC2 }}$ with or without PX12 $(50 \mu M)$ were stained with annexin V and PI and then analyzed by flow cytometry. The bar chart shows the quantification. **, $\mathrm{P}<0.01$; ${ }^{* *}, \mathrm{P}<0.001$. ns, not significant./ MSC, mesenchymal stem cell; STC2, stanniocalcin-2; ROS, reactive oxygen species; PI, propidium iodide.

TNF- $\alpha$ and reduced IL-10 or CD206 expression in THP1 cells, respectively (Figure 3). Collectively, these results indicated that STC2 and MSCs apoptosis are involved in the modulation of macrophages polarization from M1 to M2 phenotype.

\section{STC2 knockdown attenuated the reparable effects of MSCs on LPS-induced ALI}

The LPS-induced ALI was identified histopathologically and characterized by lung edema, thickening of the alveolar walls and interstitium, and alveolar spaces filled with mononuclear/ neutrophilic infiltrates. The injured areas and numbers of infiltrative neutrophils in the LPS + MSC $^{\text {shNTC }}$ group were dramatically reduced compared to the LPS treatment group. However, the reparable effects of MSCs on LPS-induced ALI were significantly attenuated in the LPS $+M S C^{\text {shSTC2 }}$ group. These features were consistent with calculated lung injury scores (Figure 4A,B). In BALF, MSCs significantly suppressed LPS-induced leukocyte accumulation, which was 

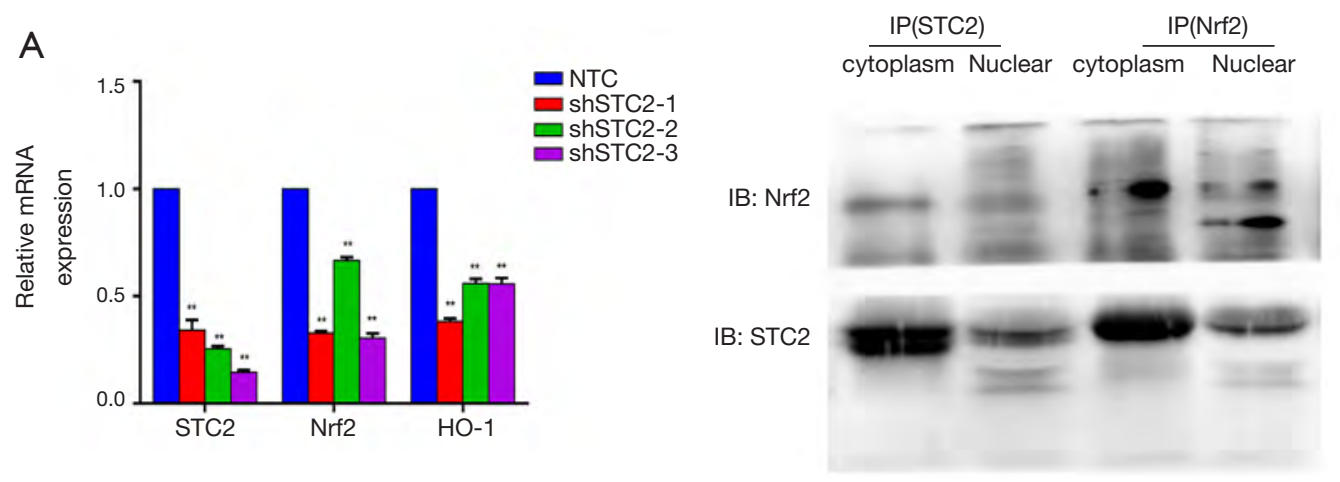

B

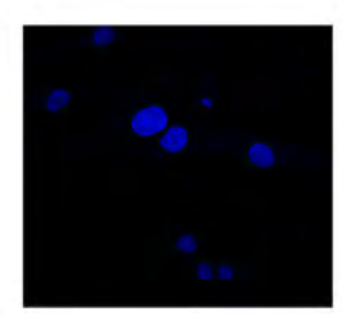

Nrf2

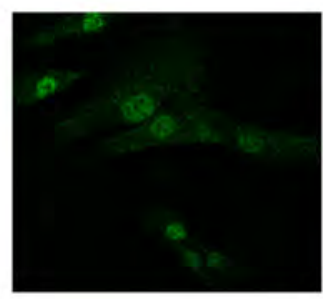

STC2

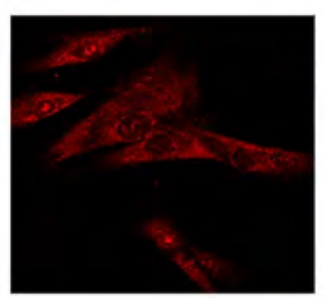

Merge

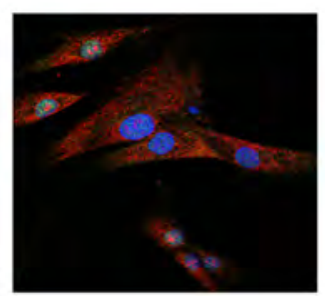

Figure 2 STC2 colocalized with Nrf2 in MSCs. (A) The relative mRNA expression levels of STC2, Nrf2, and HO1 were analyzed by quantitative polymerase chain reaction (qPCR); (B) distributions of STC2 and Nrf2 in MSC were examined by a confocal fluorescence microscope; (C) the association of STC2 and Nrf2 was analyzed by CO-IP. shSTC2 vs. NTC, **, P<0.05. IP, immunoprecipitation; STC2, stanniocalcin-2; MSC, mesenchymal stem cell.

robustly attenuated in the LPS+MSC ${ }^{\text {shSTC2 }}$ group (Figure $4 C$ ). The pulmonary vascular permeability was measured by Evans Blue assay. MSC ${ }^{\text {shSTC2 }}$ showed a significant decrease in the permeability (Figure 4D). IL-17A and TNF- $\alpha$ are key cytokines for indexing lung inflammation (4,36). After LPS treatment, the concentration of IL-17A and TNF in the BALF increased significantly, and both were inhibited when MSC $^{\text {shNTC }}$ was administered. However, MSC ${ }^{\text {shSTC2 }}$ dramatically reduced TNF- $\alpha$ inhibition more than MSC ${ }^{\text {shNTC }}$ (Figure 4E,F). To summarize, these results showed that STC2 plays a crucial role in MSCs-mediated reparable effects on LPS-induced ALI.

\section{STC2-depleted MSCs failed to induce AM phenotype transition to phenotype M2}

To further investigate MSCs induced AM polarization in vivo, BALF cells were collected in MSCs-treated mice and stained with F4/80, TNF- $\alpha$, and CD206, followed by flow cytometry analysis. Results showed that LPS promoted AM to express TNF- $\alpha$ while MSCs prevented it. Meanwhile, MSCs induced the expression of CD206 in AM. However, the STC2 knockdown reduced these phenomena (Figure $5 A$ ). This result demonstrated that STC2 suppressed LPSinduced AM transition to the M1 phenotype and is essential for MSCs-mediated anti-inflammatory function in ALI.

\section{STC2 deficient MSCs reduced antioxidant capacity to ALI}

Since cell survival and apoptosis are related to its antioxidative properties (37), we measured the antioxidant activity changes in $\mathrm{MSC}^{\text {shSTC2 }}$-treated injured lungs. Total SOD activity (Figure 5B) and GSH/GSSG ratio (Figure 5C) were significantly decreased after LPS challenge. MSC ${ }^{\text {shNTC }}$ administration restored these antioxidant activities in the injured lung. However, STC2 knockdown reduced the antioxidant capacities of MSCs in lung injury. These results revealed that the expression of STC2 is also crucial for MSC antioxidant capacity.

\section{STC2 attenuated MSC apoptosis induced by BALF}

BALF from injured lungs is rich in oxidative molecules (38). 


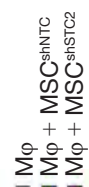

110

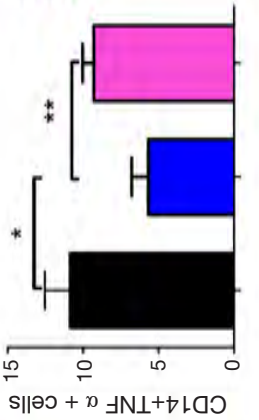

n
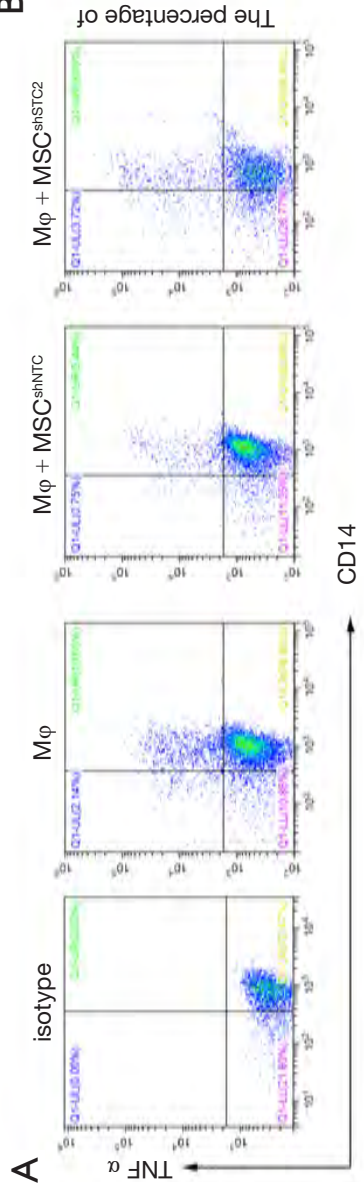

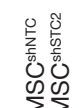

$\sum \sum$

$\sum^{2} \sum^{\circ} \sum^{\circ}$

100

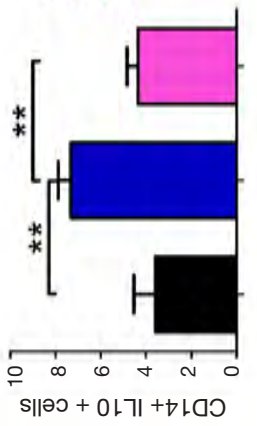

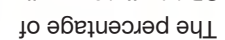
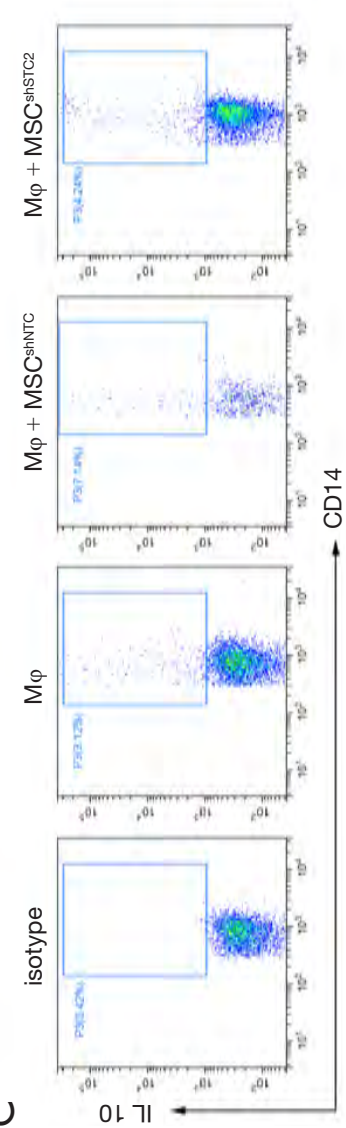

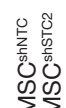

$\sum \sum$

$\sum^{e} \sum^{\theta} \sum^{\theta}$

II

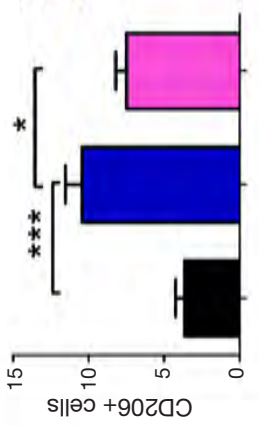

ए
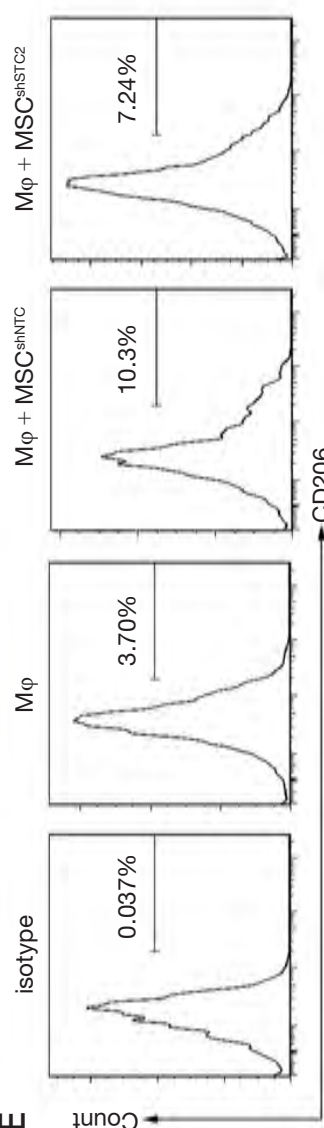

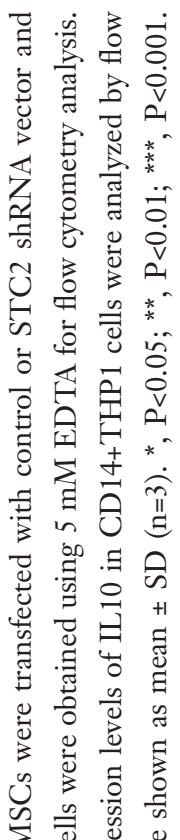

¿ षे

这司

莡寻

\&ै

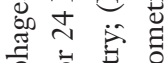

วิ

苞市

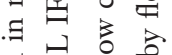

톯

की

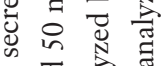

范芯芯

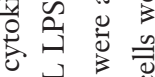

ㄹ.

웜

当

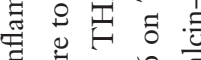

‡

ప

¿

考昰

$\Xi$ य

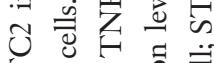

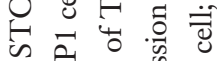

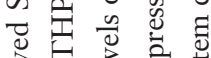

.

造高

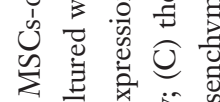

$m$ 可

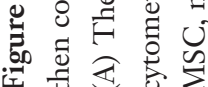


A
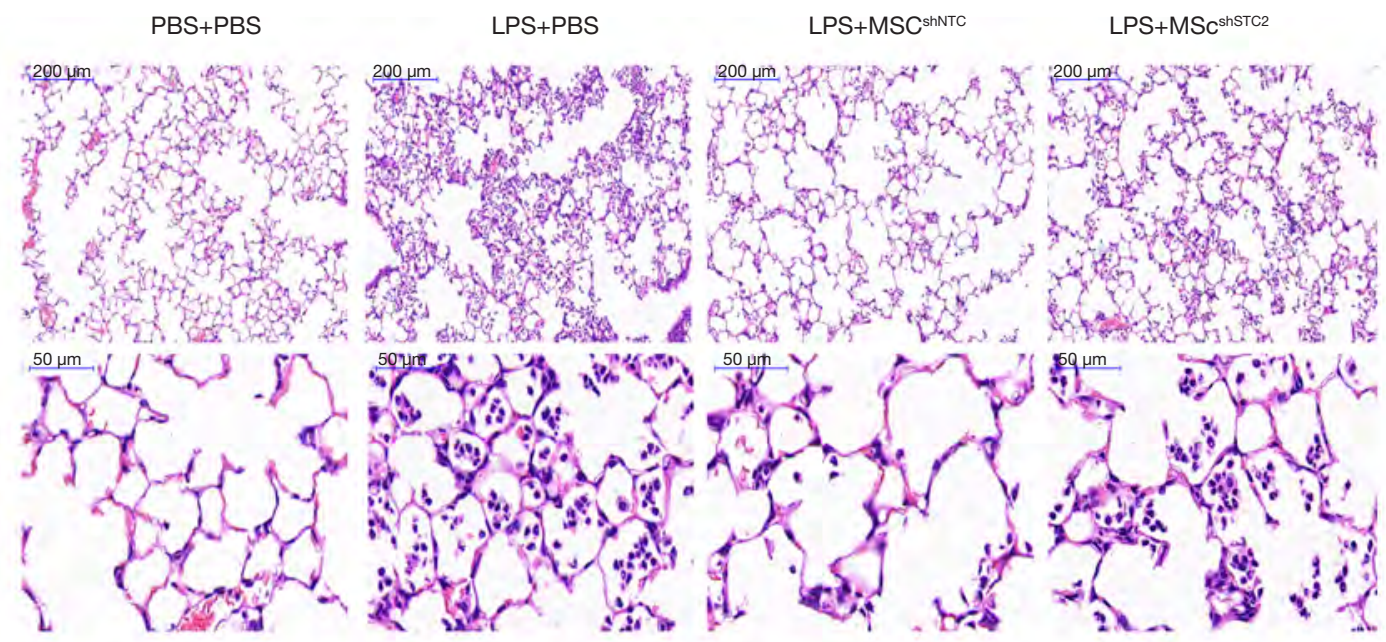

B
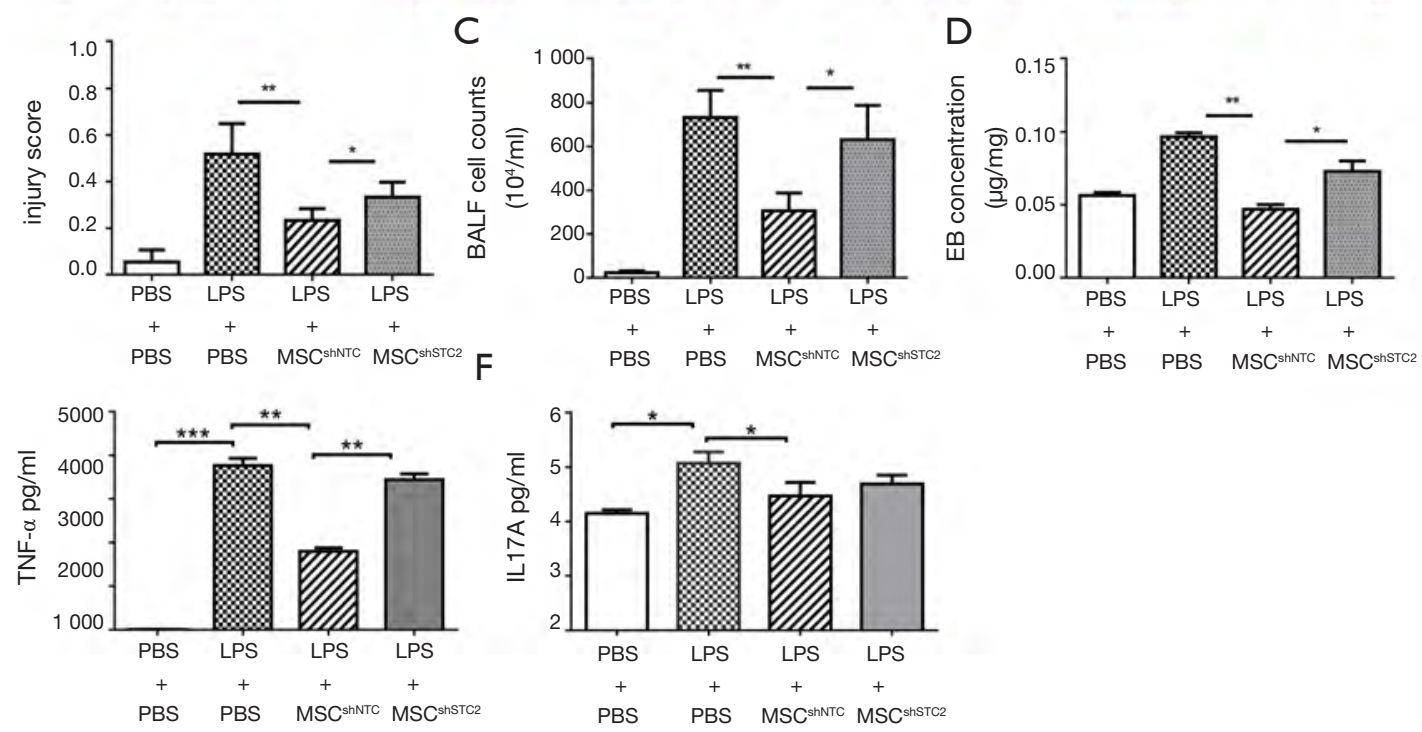

Figure 4 STC2 contributed to MSCs-mediated ameliorating effects on LPS-induced ALI. Male adult BALB/c mice (8 to 10 weeks old) were randomly divided into four different groups: PBS + PBS, LPS + PBS, LPS + MSC ${ }^{\text {shNTC }}$, and LPS + MSC ${ }^{\text {shSTC2}}$. The ALI model was established by LPS $(5 \mathrm{mg} / \mathrm{kg})$ installation intranasally. The control group received the same volume of PBS. The mice were killed to obtain lung tissues $24 \mathrm{~h}$ after LPS treatment or were used to collect BALF. (A) The degree of lung injury was assessed with H\&E staining; (B) histopathological mean lung injury scores; (C) neutrophil count in BALF; (D) the pulmonary permeability index was measured by Evans blue dye. TNF- $\alpha(\mathrm{E})$ and IL-17A (F) levels in BALF were detected using ELISA assay. $\mathrm{n}=10$ each group. ${ }^{*}, \mathrm{P}<0.05 ;{ }^{* *}, \mathrm{P}<0.01 ;{ }^{* * *}, \mathrm{P}<0.001$. STC2, stanniocalcin-2; MSC, mesenchymal stem cell; ALI, acute lung injury; BALF, bronchoalveolar lavage fluid; ELISA, enzyme-linked immunosorbent assay.

MSCs are susceptible to oxidative stress, affecting their viability (39). We used BALF obtained from the LPSinduced ALI (BALF-LPS) group and the control (BALFPBS) group to treat control MSCs and STC2-depleted MSCs. Figure $6 A$ shows that BALF-LPS treatment significantly increased $\mathrm{MSC}^{\mathrm{shSTC2}}$ apoptosis compared with MSC $^{\text {shNTC }}$ in the BALF-PBS group. In addition, to measure
MSC survival in LPS-induced ALI, BALF was then collected from CFSE-labeled MSCs-treated mice at 24 and $48 \mathrm{~h}$. CFSE /PI positive cells in the BALF were analyzed by FACS. The MSC ${ }^{\text {shSTC2}}$ apoptosis in BALF collected at $48 \mathrm{~h}(10.1 \%)$ after LPS treatment was higher than in that collected at $24 \mathrm{~h}(7.77 \%)$ compared with $\mathrm{MSC}^{\text {shNTC }}$ (Figure $6 B)$. The results showed that STC2 is involved in BALF- 

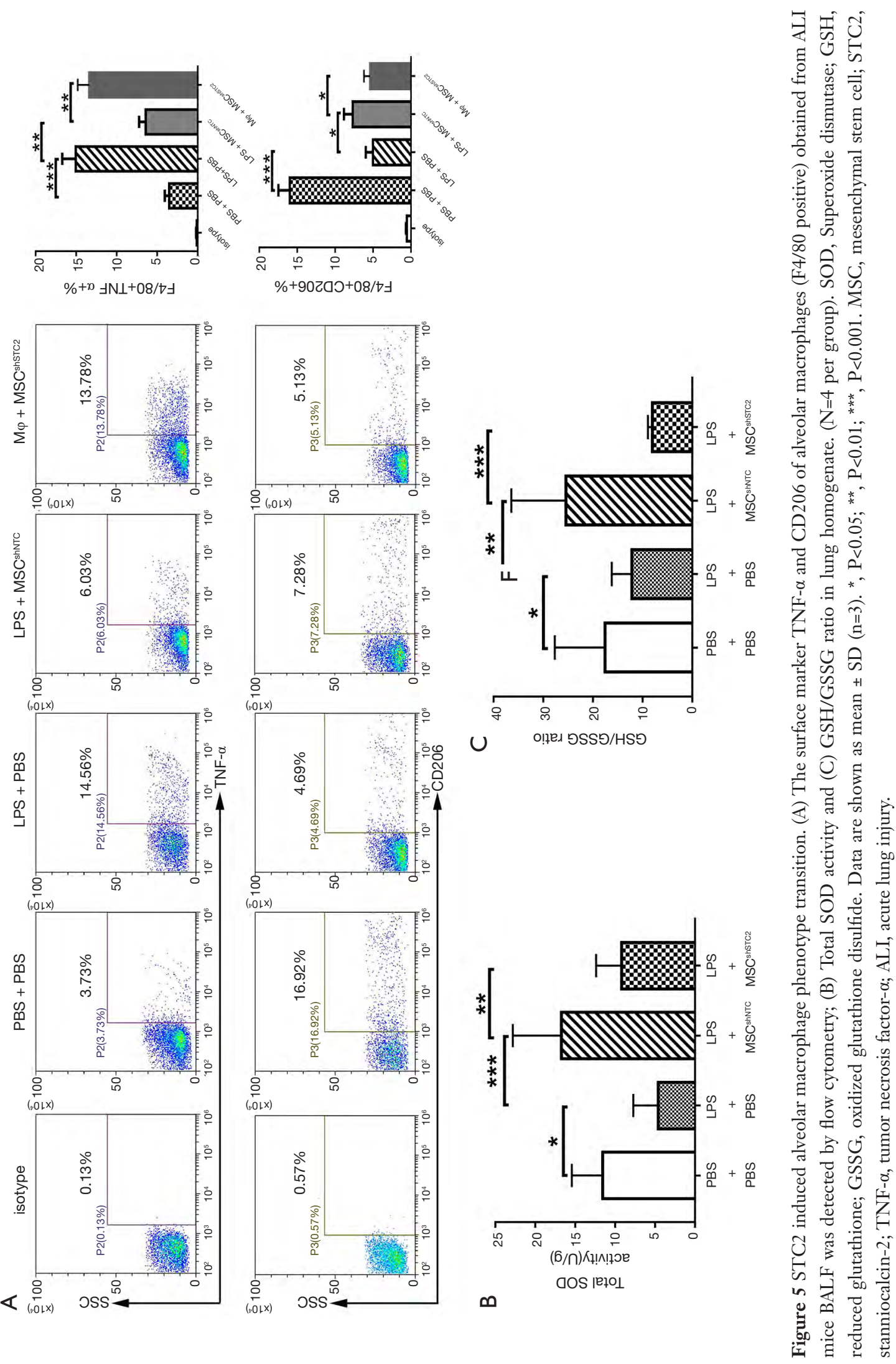

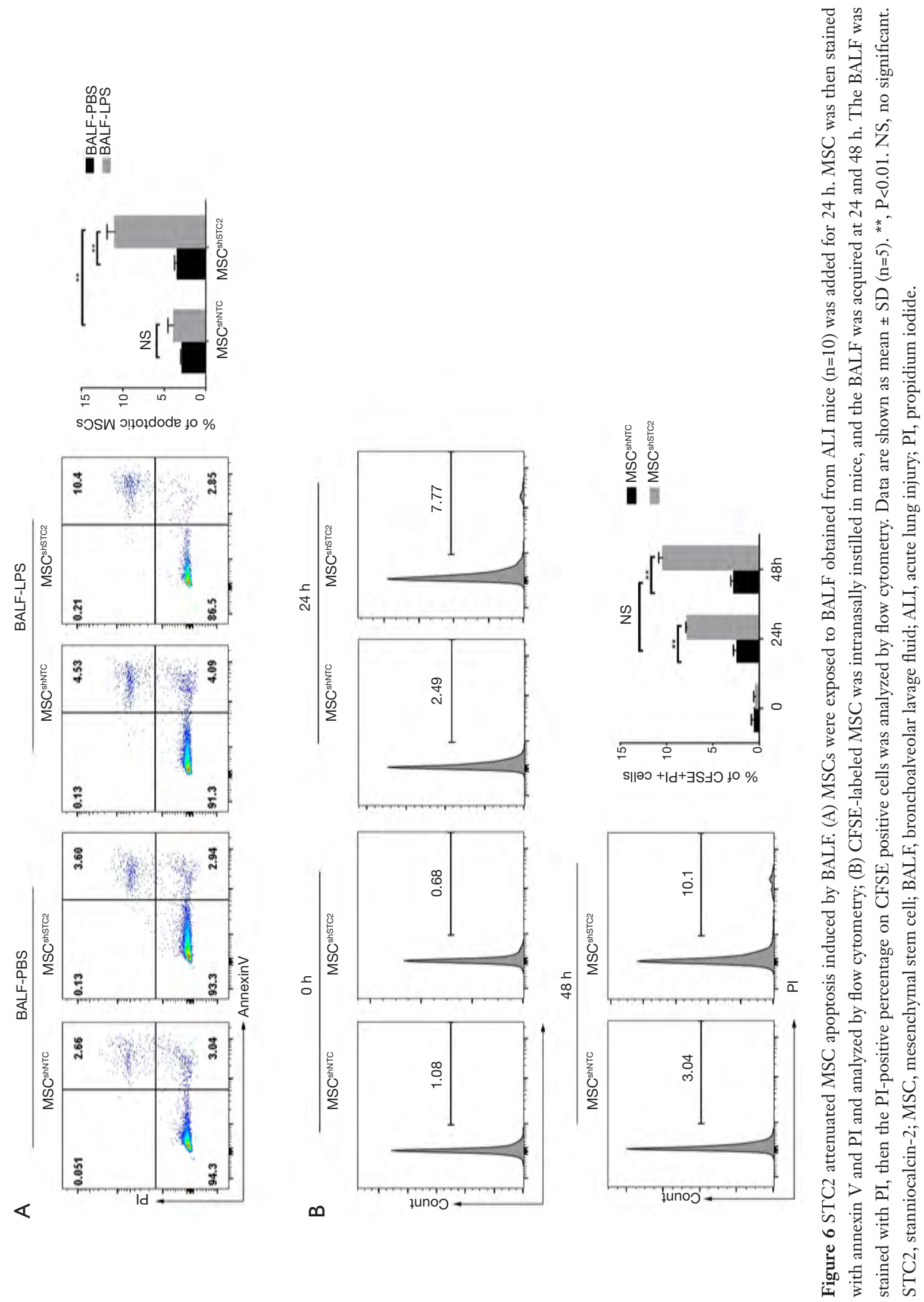
induced MSCs apoptosis and plays an important role in the anti-apoptosis effect of MSCs.

\section{Discussion}

ALI is a comprehensive syndrome with excessive inflammation and oxidative stress response $(1,40)$. However, there is still no effective pharmacological therapy $(5,6)$. Cell-based therapy has emerged as a potential novel therapy for ALI (12), but the specific mechanism has not been thoroughly scrutinized. In this study, we found that STC2 is essential to MSCs antioxidative and anti-inflammatory properties, and first reported that STC2-mediated MSCs survival maintenance in vivo and AMs polarization is crucial for repair in LPS-induced ALI.

Cell oxidative stress responses are often associated with survival and inflammation (37). Expressing stress response genes like HO-1, Nrf2, and STCs, have pivotal roles for MSCs anti-inflammatory and cytoprotective properties. The activation of the Nrf2/ HO-1 signaling pathway suppresses oxidative stress and inflammation reactions in LPS-induced ALI (41). MSC overexpression of Nrf2 or HO-1 exerts antioxidant and anti-inflammatory effects $(23,42)$. STC1 ameliorates LPS-induced pulmonary oxidative stress, inflammation, and apoptosis (28). STC2 contributes to macrophage foam cell formation (32) and enhances MSCs survival by suppressing oxidative stress (33). Our previous study also found STC2 is a highly expressed stanniocalcin that colocalizes with HO-1 in the cytoplasm in MSCs and is crucial for MSCs attenuating allergic contact dermatitis (ACD) by reducing IFN- $\gamma$ - and TNF- $\alpha$-producing CD $8^{+}$ $\mathrm{T}$ cells (30). We reported for the first time that STC2 colocalized with Nrf2 in MSCs nucleis. Silencing STC2 significantly reduced MSCs activity in relation to polarizing macrophage and resistance to oxidative stress. This evidence firmly introduces STC2 as a novel factor for MSCs' antiinflammatory and antioxidant effects.

In vivo studies, numerous researchers have investigated the importance of AM and oxidative response in ALI (10). AM polarization predicted the resolution of acute inflammation in the lungs (43) and redox signaling has related implications (44). Previous studies have found that PGE2 and TSG6 are the most potent anti-inflammatory paracrine factors known from MSC to induce AM phenotype transition $(45,46)$. Here, we found that STC2 was also a key factor for AM polarization in ALI. Knocking down STC2 influences IL10 but not TSG6 secretion. Combined with the above findings, it indicates that MSCs exert a protective effect via an anti-inflammatory redoxoxidant revolving axis (47).

Oxidative stress responses are dominant features of the progression of ALI $(40,48)$. Oxidative stress-induced apoptosis is one of the primary reasons for the poor viability of MSCs in vivo (49). We investigated the anti-inflammatory effect from apoptotic MSCs and found that apoptotic MSCs significantly diminished macrophage polarization. This was consistent with preclinical and clinical studies $(18,50)$. Additionally, BALF insulted MSCs or STC2-deficient MSCs from injured lungs are more prone to apoptosis. That suggests that STC2 is partially involved MSCs survival in vivo and may be a promising target to improve its therapeutic effect.

\section{Conclusions}

In summary, we reported that the expression of STC2 in MSCs is essential to their anti-oxidant and antiinflammation properties. STC2 suppressed the production of ROS, and reduced the apoptosis rate in MSCs under stress in vitro and in vivo, mediated by interacting with Nrf2. Silencing STC2 in MSCs inhibited their ameliorating effect on LPS-induced ALI. Our findings suggest that MSCs-derived STC2 might represent a promising novel therapeutic target for the treatment of ALI.

\section{Acknowledgments}

Funding: This work was supported by the Major State Research Development Program (2017ZX10203205-006001, 2017ZX10203205-001-003); The National Natural Science Foundation of China [grant number 81601381, 81971526, 81670601, 81770648]; the Natural Science Foundation of Guangdong Province [grant number 2016A030310131, 2018A030313259]; the Fundamental Research Funds for the Central Universities [grant number 17ykpy50].

\section{Footnote}

Conflicts of Interest: The authors have no conflicts of interest to declare.

Ethical Statement: The authors are accountable for all aspects of the work in ensuring that questions related to the accuracy or integrity of any part of the work are appropriately investigated and resolved. The study and all 
procedures were approved by the Animal Care and Use Committee of Animal Welfare Ethics Committee of Sun Yat-sen University Vaccine Research Institute (approval number IACUC-F3-16-0401). Informed consent was obtained from all individual participants included in the study.

Open Access Statement: This is an Open Access article distributed in accordance with the Creative Commons Attribution-NonCommercial-NoDerivs 4.0 International License (CC BY-NC-ND 4.0), which permits the noncommercial replication and distribution of the article with the strict proviso that no changes or edits are made and the original work is properly cited (including links to both the formal publication through the relevant DOI and the license). See: https://creativecommons.org/licenses/by-nc-nd/4.0/.

\section{References}

1. Thompson BT, Chambers RC, Liu KD. Acute Respiratory Distress Syndrome. N Engl J Med 2017;377:562-72.

2. ARDS Definition Task Force, Ranieri VM, Rubenfeld GD, et al. Acute respiratory distress syndrome: the Berlin Definition. JAMA 2012;307:2526-33.

3. Bellani G, Laffey JG, Pham T, et al. Epidemiology, Patterns of Care, and Mortality for Patients With Acute Respiratory Distress Syndrome in Intensive Care Units in 50 Countries. JAMA 2016;315:788-800.

4. Matute-Bello G, Downey G, Moore BB, et al. An official American Thoracic Society workshop report: features and measurements of experimental acute lung injury in animals. Am J Respir Cell Mol Biol 2011;44:725-38.

5. Papazian L, Aubron C, Brochard L, et al. Formal guidelines: management of acute respiratory distress syndrome. Ann Intensive Care 2019;9:69.

6. Impellizzeri D, Bruschetta G, Esposito E, et al. Emerging drugs for acute lung injury. Expert Opin Emerg Drugs 2015;20:75-89.

7. Herold S, Mayer K, Lohmeyer J. Acute lung injury: how macrophages orchestrate resolution of inflammation and tissue repair. Front Immunol 2011;2:65.

8. Huang X, Xiu H, Zhang S, et al. The Role of Macrophages in the Pathogenesis of ALI/ARDS. Mediators Inflamm 2018;2018:1264913.

9. Wang J, Wakeham J, Harkness R, et al. Macrophages are a significant source of type 1 cytokines during mycobacterial infection. J Clin Invest 1999;103:1023-9.

10. Aggarwal NR, King LS, D'Alessio FR. Diverse macrophage populations mediate acute lung inflammation and resolution. Am J Physiol Lung Cell Mol Physiol 2014;306:L709-25.

11. Matthay MA, Pati S, Lee JW. Concise Review: Mesenchymal Stem (Stromal) Cells: Biology and Preclinical Evidence for Therapeutic Potential for Organ Dysfunction Following Trauma or Sepsis. Stem Cells 2017;35:316-24.

12. Laffey JG, Matthay MA. Fifty Years of Research in ARDS. Cell-based Therapy for Acute Respiratory Distress Syndrome. Biology and Potential Therapeutic Value. Am J Respir Crit Care Med 2017;196:266-73.

13. Hu S, Li J, Xu X, et al. The hepatocyte growth factorexpressing character is required for mesenchymal stem cells to protect the lung injured by lipopolysaccharide in vivo. Stem Cell Res Ther 2016;7:66.

14. Chan MC, Kuok DI, Leung CY, et al. Human mesenchymal stromal cells reduce influenza A H5N1associated acute lung injury in vitro and in vivo. Proc Natl Acad Sci U S A 2016;113:3621-6.

15. Carty F, Mahon BP, English K. The influence of macrophages on mesenchymal stromal cell therapy: passive or aggressive agents? Clin Exp Immunol 2017;188:1-11.

16. von Bahr L, Batsis I, Moll G, et al. Analysis of tissues following mesenchymal stromal cell therapy in humans indicates limited long-term engraftment and no ectopic tissue formation. Stem Cells 2012;30:1575-8.

17. de Witte SFH, Luk F, Sierra Parraga JM, et al. Immunomodulation By Therapeutic Mesenchymal Stromal Cells (MSC) Is Triggered Through Phagocytosis of MSC By Monocytic Cells. Stem Cells 2018;36:602-15.

18. Matthay MA, Calfee CS, Zhuo H, et al. Treatment with allogeneic mesenchymal stromal cells for moderate to severe acute respiratory distress syndrome (START study): a randomised phase 2 a safety trial. The Lancet Respiratory Medicine 2019;7:154-62.

19. Gupta N, Su X, Popov B, et al. Intrapulmonary delivery of bone marrow-derived mesenchymal stem cells improves survival and attenuates endotoxin-induced acute lung injury in mice. J Immunol 2007;179:1855-63.

20. Kizilay Mancini O, Lora M, Cuillerier A, et al. Mitochondrial Oxidative Stress Reduces the Immunopotency of Mesenchymal Stromal Cells in Adults With Coronary Artery Disease. Circ Res 2018;122:255-66.

21. Chen X, Wu S, Tang L, et al. Mesenchymal stem cells overexpressing heme oxygenase- 1 ameliorate lipopolysaccharide-induced acute lung injury in rats. J Cell Physiol 2019;234:7301-19. 
22. Zhang S, Jiang W, Ma L, et al. Nrf2 transfection enhances the efficacy of human amniotic mesenchymal stem cells to repair lung injury induced by lipopolysaccharide. J Cell Biochem 2018;119:1627-36.

23. Chen X, Zhang Y, Wang W, et al. Mesenchymal Stem Cells Modified with Heme Oxygenase-1 Have Enhanced Paracrine Function and Attenuate LipopolysaccharideInduced Inflammatory and Oxidative Damage in Pulmonary Microvascular Endothelial Cells. Cell Physiol Biochem 2018;49:101-22.

24. Bonga SW, Pang P. Control of calcium regulating hormones in the vertebrates: parathyroid hormone, calcitonin, prolactin, and stanniocalcin. International review of cytology. Elsevier, 1991:139-213.

25. Roche FP, Pietila I, Kaito H, et al. Leukocyte Differentiation by Histidine-Rich Glycoprotein/ Stanniocalcin-2 Complex Regulates Murine Glioma Growth through Modulation of Antitumor Immunity. Mol Cancer Ther 2018;17:1961-72.

26. Law AY, Wong CK. Stanniocalcin-1 and -2 promote angiogenic sprouting in HUVECs via VEGF/VEGFR2 and angiopoietin signaling pathways. Mol Cell Endocrinol 2013;374:73-81.

27. Esawy MM, Shabana MA, Baioumy SA, et al. Diagnostic and prognostic roles of peripheral blood Toll-like receptor-4 and stanniocalcin-1 genes expression in acute lung injury. Immunobiology 2019;224:734-8.

28. Tang SE, Wu CP, Wu SY, et al. Stanniocalcin-1 ameliorates lipopolysaccharide-induced pulmonary oxidative stress, inflammation, and apoptosis in mice. Free Radic Biol Med 2014;71:321-31.

29. Fu R, Li Q, Fan R, et al. iTRAQ-based secretome reveals that $\mathrm{SiO} 2$ induces the polarization of RAW264.7 macrophages by activation of the NOD-RIP2-NFkappaB signaling pathway. Environ Toxicol Pharmacol 2018;63:92-102.

30. Chen X, Liu Q, Huang W, et al. Stanniocalcin-2 contributes to mesenchymal stromal cells attenuating murine contact hypersensitivity mainly via reducing CD8(+) Tc1 cells. Cell Death Dis 2018;9:548.

31. Jiang J, Westberg JA, Andersson LC. Stanniocalcin 2, forms a complex with heme oxygenase 1, binds hemin and is a heat shock protein. Biochem Biophys Res Commun 2012;421:274-9.

32. Yamamoto K, Tajima Y, Hasegawa A, et al. Contrasting effects of stanniocalcin-related polypeptides on macrophage foam cell formation and vascular smooth muscle cell migration. Peptides 2016;82:120-7.
33. Kim PH, Na SS, Lee B, et al. Stanniocalcin 2 enhances mesenchymal stem cell survival by suppressing oxidative stress. BMB Rep 2015;48:702-7.

34. Byun JS, Lee JW, Kim SY, et al. Neuroprotective effects of stanniocalcin 2 following kainic acid-induced hippocampal degeneration in ICR mice. Peptides 2010;31:2094-9.

35. Zhang L, Li Q, Liu W, et al. Mesenchymal stem cells alleviate acute lung injury and inflammatory responses induced by paraquat poisoning. 2019;25:2623.

36. Mikacenic C, Hansen EE, Radella F, et al. Interleukin17A Is Associated With Alveolar Inflammation and Poor Outcomes in Acute Respiratory Distress Syndrome. Crit Care Med 2016;44:496-502.

37. Portt L, Norman G, Clapp C, et al. Anti-apoptosis and cell survival: a review. Biochim Biophys Acta 2011;1813:238-59.

38. Jarikre TA, Ohore GO, Oyagbemi AA, et al. Evaluation of oxidative stress in caprine bronchoalveolar lavage fluid of pneumonic and normal lungs. Int J Vet Sci Med 2017;5:143-7.

39. Amiri F, Jahanian-Najafabadi A, Roudkenar MH. In vitro augmentation of mesenchymal stem cells viability in stressful microenvironments: In vitro augmentation of mesenchymal stem cells viability. Cell Stress Chaperones 2015;20:237-51.

40. Ward PA. Oxidative stress: acute and progressive lung injury. Ann N Y Acad Sci 2010;1203:53-9.

41. Meng X, Hu L, Li W. Baicalin ameliorates lipopolysaccharide-induced acute lung injury in mice by suppressing oxidative stress and inflammation via the activation of the Nrf2-mediated HO-1 signaling pathway. Naunyn Schmiedebergs Arch Pharmacol 2019;392:1421-33.

42. Mohammadzadeh M, Halabian R, Gharehbaghian A, et al. Nrf-2 overexpression in mesenchymal stem cells reduces oxidative stress-induced apoptosis and cytotoxicity. Cell Stress Chaperones 2012;17:553-65.

43. Benoit M, Desnues B, Mege JL. Macrophage polarization in bacterial infections. J Immunol 2008;181:3733-9.

44. Tan HY, Wang N, Li S, et al. The Reactive Oxygen Species in Macrophage Polarization: Reflecting Its Dual Role in Progression and Treatment of Human Diseases. Oxid Med Cell Longev 2016;2016:2795090.

45. Németh K, Leelahavanichkul A, Yuen PS, et al. Bone marrow stromal cells attenuate sepsis via prostaglandin $\mathrm{E}(2)$-dependent reprogramming of host macrophages to increase their interleukin-10 production. Nat Med 2009; 15:42-9. 
46. Mittal M, Tiruppathi C, Nepal S, et al. TNFalphastimulated gene-6 (TSG6) activates macrophage phenotype transition to prevent inflammatory lung injury. Proc Natl Acad Sci U S A 2016;113:E8151-8.

47. Haddad JJ, Fahlman CS. Redox- and oxidant-mediated regulation of interleukin-10: an anti-inflammatory, antioxidant cytokine? Biochem Biophys Res Commun 2002;297:163-76.

48. Chow CW, Herrera Abreu MT, Suzuki T, et al. Oxidative stress and acute lung injury. Am J Respir Cell Mol Biol

Cite this article as: Lv H, Liu Q, Sun Y, Yi X, Wei X, Liu W, Zhang Q, Yi H, Chen G. Mesenchymal stromal cells ameliorate acute lung injury induced by LPS mainly through stanniocalcin-2 mediating macrophage polarization. Ann Transl Med 2020;8(6):334. doi: 10.21037/atm.2020.02.105
2003;29:427-31.

49. Chang W, Song BW, Moon JY, et al. Anti-death strategies against oxidative stress in grafted mesenchymal stem cells. Histol Histopathol 2013;28:1529-36.

50. Sun J, Han ZB, Liao W, et al. Intrapulmonary delivery of human umbilical cord mesenchymal stem cells attenuates acute lung injury by expanding CD4+CD25+ Forkhead Boxp3 (FOXP3)+ regulatory $\mathrm{T}$ cells and balancing antiand pro-inflammatory factors. Cell Physiol Biochem 2011;27:587-96. 


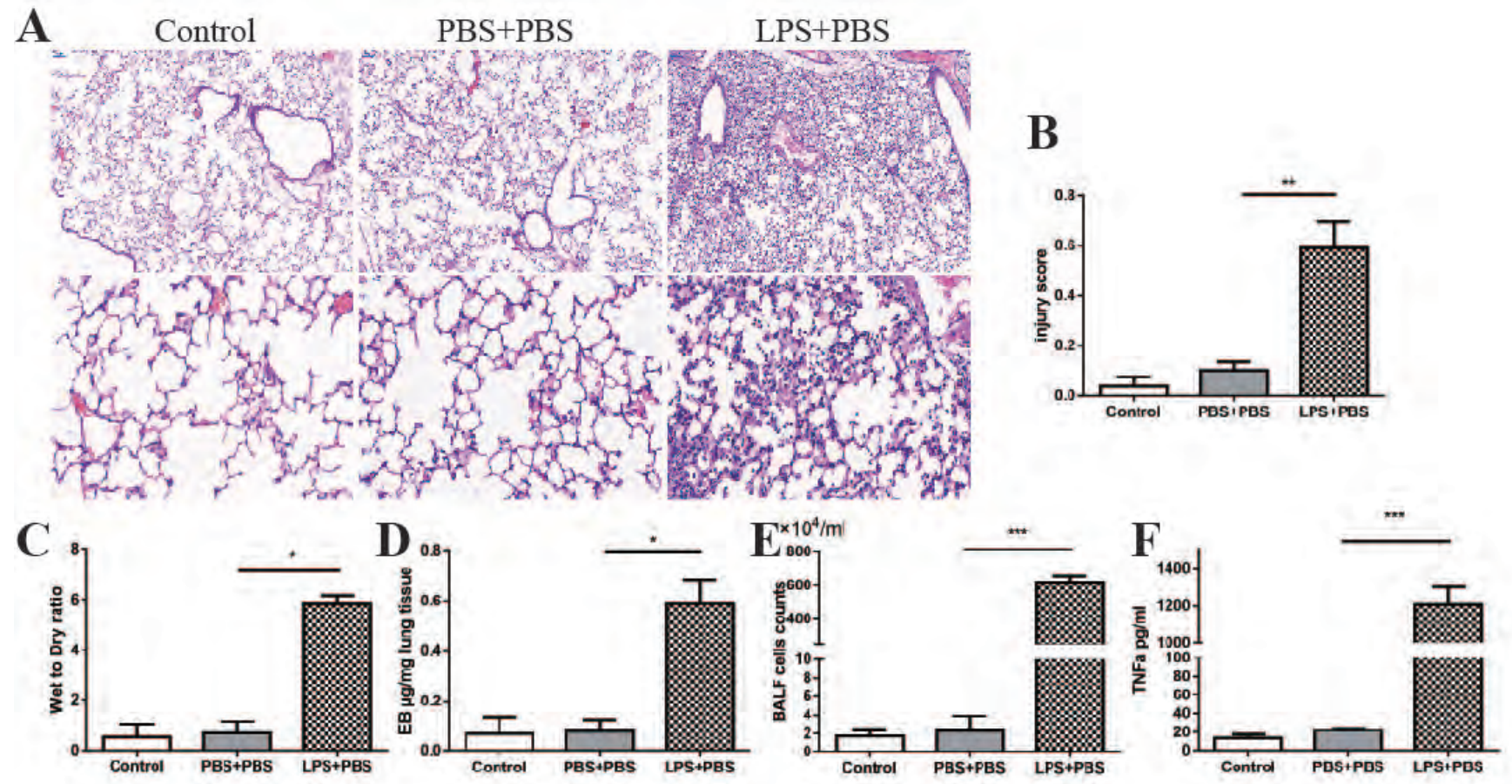

Figure S1 Murine acute lung injury model and measurement. Control group without any stimuli, PBS + PBS group and LPS + PBS group mice were intratracheal instilled with $30 \mu \mathrm{L}$ PBS or $30 \mu \mathrm{L}(5 \mathrm{mg} / \mathrm{kg}) \mathrm{LPS}, 4$ hours later, $30 \mu \mathrm{L}$ PBS were instilled again. Lung histological analysis by $\mathrm{HE}$ stain (A), magnification for upper panel was $50 \times$ and lower panel was $200 \times$, lung injury score (B), permeability (wet to dry ration, C; Evans Blue dye, D), neutrophils counts (E) and TNF-a concentrations in BALF were measured. There were no significant differences of these measurements between control group and PBS + PBS group (n=3-5). * $\mathrm{P}<0.05 ;{ }^{* *}, \mathrm{P}<0.01 ;{ }^{* * *}, \mathrm{P}<0.001$. TNF- $\alpha$, tumor necrosis factor- $\alpha$; BALF, bronchoalveolar lavage fluid.

A

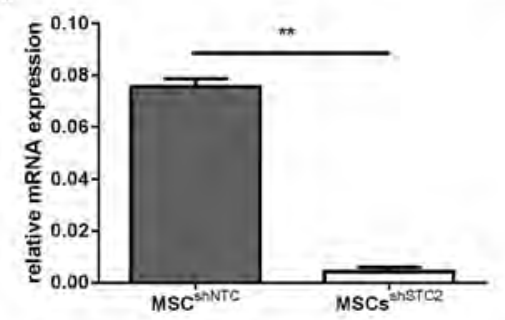

B

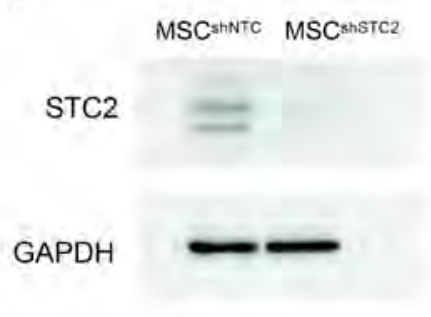

Figure S2 The relative mRNA expression levels of STC2 analyzed by qPCR and normalized with reference GAPDH controls (A, n=3 for each group). Representative western blot analysis of STC2 expression in MSCs (B). Data are shown as mean \pm SD. ${ }^{* *}, \mathrm{P}<0.01$. MSC, mesenchymal stem cell; STC2, stanniocalcin-2; qPCR, quantitative polymerase chain reaction. 


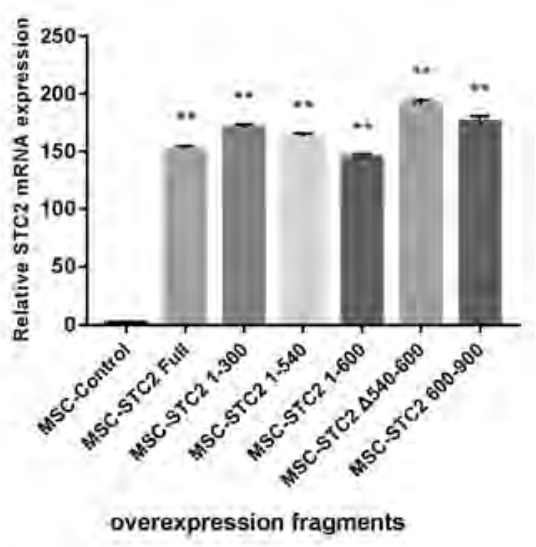

Figure S3 The diagrammatic sketch of overexpressed constructs of STC2 in MSCs. The relative mRNA expression levels of STC2 were analyzed by qPCR and normalized with reference GAPDH controls. Multiple $t$-tests were used in comparison between each overespressed genotype and MSCcontrol ( $\mathrm{n}=3$ for each group). Data are shown as mean \pm SD. ${ }^{* *}, \mathrm{P}<0.01$. MSC, mesenchymal stem cell; STC2, stanniocalcin-2; qPCR, quantitative polymerase chain reaction.

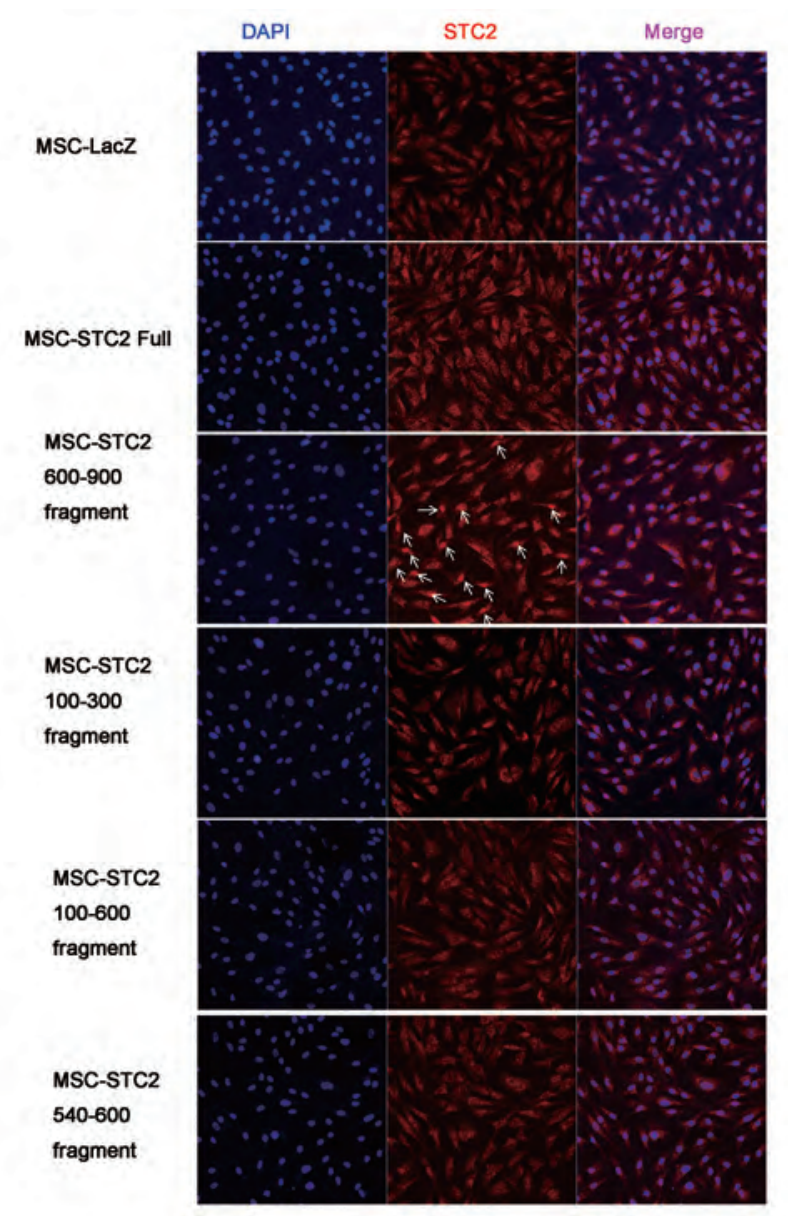

Figure S4 The location of STC2 in MSCs when overexpressed with different constructs. Nucleus were stained with DAPI (blue), STC2 were stained with monoclonal antibody (red). The amino acids 600-900 fragment was highly expressed in nuclei (arrows). Magnification in each field was 400×. STC2, stanniocalcin-2; MSC, mesenchymal stem cell. 

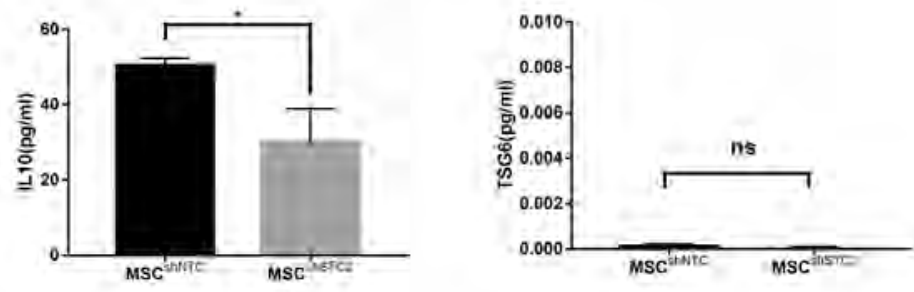

Figure S5 The secretion of IL-10 (left) and TSG6 (right) from STC2 silenced MSCs or control MSCs detected by ELISA. IL-10, interleukin 10; TSG6, tumor necrosis factor $\alpha$ stimulated gene 6. Data are shown as mean \pm SD $(n=3)$. * $P<0.05$. STC2, stanniocalcin-2; MSC, mesenchymal stem cell; ELISA, enzyme-linked immunosorbent assay.
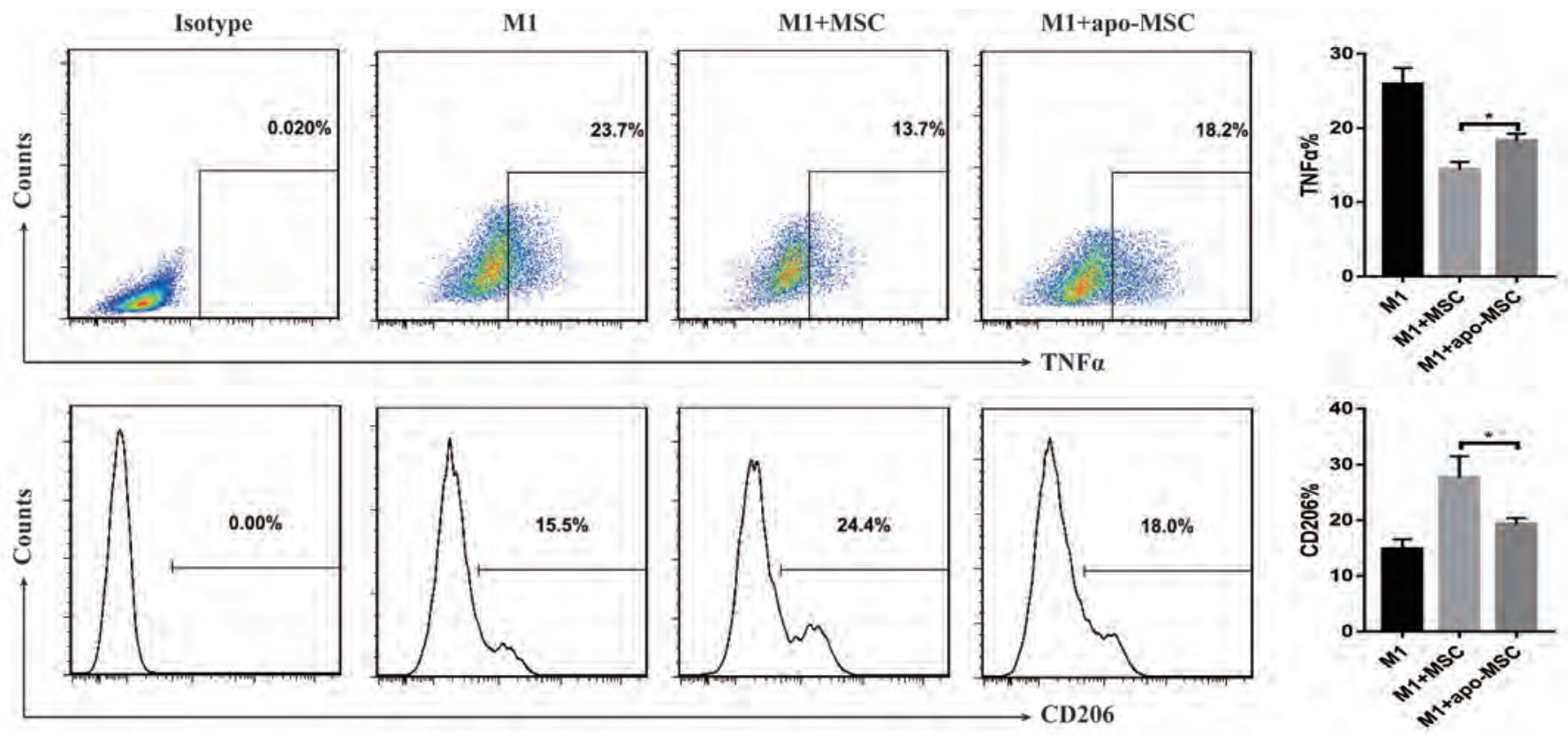

Figure S6 Apoptotic MSC failed to induce macrophage polarization. MSCs were exposed to PX12 (50 $\mu$ M) for 24 hours to induce apoptotic MSCs (apo-MSCs). Then MSCs control or apo-MSCs were cocultured with inflammatory insulted (LPS $1 \mu \mathrm{g} / \mathrm{mL}, \mathrm{INF} \gamma 50 \mathrm{ng} / \mathrm{mL}) \mathrm{THP} 1$ cells (M1) for a further 24 hours. THP1 was stained with CD206, TNF $\alpha$ and analyzed by flow cytometry. Data are shown as mean \pm SD ( $=3$ ). *, $\mathrm{P}<0.05$. MSC, mesenchymal stem cell; TNF- $\alpha$, tumor necrosis factor- $\alpha$. 